Background Research shows that palliative care for children requires special attention and a coordinated approach to support the child and its entire family. In June 2012 a project was started in the Women's and Children's Clinic, Academic Medical Centre, Amsterdam, the Netherlands.

The aim of this project is to give a child with a life threatening or life limiting illness the highest possible quality of life and to relieve parents from all coordination tasks.

Methods We developed a multi-disciplinary team of professionals, called the Emma Home Team (EHT), to support families with a child in the palliative phase. A case manager (a paediatric nurse) visits the family at home and coordinates the care in collaboration with parents and professionals to provide a unique situation for each family.

When the treatment period has finished the case manager evaluates the care with the parents and professionals involved.

Results In the last 18 months over 90 families were supported by the EHT. In 32 cases the care is finished and evaluated. These evaluations all show the importance of the coordinating function of the case manager. Parents who were supported by the EHT indicated that the commitment, expertise and accessibility of the team were a great support for them.

Conclusion The interventions by the EHT seem to have an important added value for children and families in the palliative phase. A next step is to see if this way of caregiving can be used in other hospitals.

\section{PO-0873 DETERMINATION OF FALLING RISK FOR CHILDREN IN AN EDUCATION AND RESEARCH HOSPITAL IN TURKEY}

${ }^{1} \mathrm{D}$ Suluhan, ${ }^{2} \mathrm{G}$ Aktas, ${ }^{1} \mathrm{D}$ Yildiz, ${ }^{2} \mathrm{D}$ Konukbay, ${ }^{1} \mathrm{~B}$ Fidanci, ${ }^{3}$ I Sürer, ${ }^{4} \mathrm{~V}$ Kesik. ${ }^{1}$ School of Nursing Pediatric Nursing Department, Gülhane Military Medical Academy, Ankara, Turkey; ${ }^{2}$ School of Nursing, Gülhane Military Medical Academy, Ankara, Turkey; ${ }^{3}$ Pediatric Surgery Department, Gülhane Military Medical Academy, Ankara, Turkey; ${ }^{4}$ Pediatric Oncology Department, Gülhane Military Medical Academy, Ankara, Turkey

10.1136/archdischild-2014-307384.1497

Objective The aim of this study was to determinate falling risk ofchildren who have been in Gulhane Military Medical Academy Hospital.

Methods The study wascaried out at department of paediatric surgery and department of pediatricsbetween February-March 2014 in Gulhane Military Medical Academy Hospital. Thepopulation of the study was consisted of 122 children. Diagnostic Falling RiskScale for Child Patients were used for data collection.

Results In the study group $36.1 \%$ of patients were female and $69.9 \%$ were male. The majority of patients were $<3$ years of age $(32.8 \%)$. Thereasons having been in hospital in hospital included pulmonary disease (18.6\%),neurological or neuromuscular disorders $(13.7 \%)$, and cardiac disorders (2\%), complicationsof prematurity $(8.8 \%)$, inguinal region deformity (3\%), immunological disease $(5.9 \%)$, fluid and electrolyte disorders (3.8\%),poisoning (\%3) and cancer (27.5). It was $57.4 \%$ staying in hospital which isrange from one to seven days. It was found that falling risks were high levelwhich is $97.5 \%$. There wasno stastically important difference in falling risks between gender ( $p$ ?0.005).

Conclusion It was found high falling risk for children who have beenin our hospital.

PO-0874 WITHDRAWN

\section{Nursing Adolescent Health}

\section{PO-0875 BEING AN ADOLESCENT MOTHER: A QUALITATIVE RESEARCH}

T Ayyildiz Kuzlu, M Uzun, H Kulakçi, F Veren. Nursing, Bulent Ecevit University, Zonguldak, Turkey

\subsection{6/archdischild-2014-307384.1498}

Background and aims The aim of this study was to determine the thoughts of adolescent pregnants/mothers about motherhood.

Methods A descriptive qualitative approach was used in the study. The data were obtained from 41 adolescent pregnants/ mothers with a questionnaire and open-ended semi-structured interviews in-depth audio-taped method. Data were analysed through thematic analysis by researchers.

Results Over the total amont of sample; $80.5 \%$ of adolescents didn't use a family planning method, $24.4 \%$ are relatives with her husband, $68.3 \%$ were being pregnant willingly and $24.4 \%$ didn't receive antenatal care regulary. The theme of study determined on four topics;

1) The feelings when she learn her pregnanacy

2) The meaning of baby/child in her life

3) The effect of pregnancy for her future plans

4) The troubles about care of baby/child

They mentioned hearing about their pregnancy, the first feelings were fear, sadness, wonder, happiness, shocked, rebelled and thought it wasn't the right time.

"I really surprised and feared because being a mother seemed difficult for me. Because of economical obstacle I thought that could we support the babies'care expenditure."

"I got married when I was 18. Everyone began to ask whether I am pregnant in first month period of my marriage. After three month I got pregnant. I felt that I had to be pregnant"

"I felt sadnesss, really a big sadness, cry too much, because my husband had left the house just before the news of pregnancy."

Conclusion Although pregnancy is gratifying process for a woman, it can also become discomfortable situation for adolescents.

\section{PO-0876 PEER BULLYING: KAPADOKYA IN TURKEY}

'D Evgin, ${ }^{1} \mathrm{Z}$ Caliskan, ${ }^{2} \mathrm{M}$ Bayat, ${ }^{1} \mathrm{~N}$ Goktas, ${ }^{1} \mathrm{~B}$ Kaplan, ${ }^{3} \mathrm{~A}$ Ozturk, ${ }^{2} \mathrm{D}$ Keklik. ${ }^{1}$ Nursing, Nevsehir University Semra and Vefa Küçük College of Health, Nevsehir, Turkey; ${ }^{2}$ Nursing, Erciyes University Faculty of Health Sciences Department of Nursing, Kayseri, Turkey; ${ }^{3}$ Biostatistics, Erciyes University Faculty of Medicine Department of Biostatistics, Kayseri, Turkey

\subsection{6/archdischild-2014-307384.1499}

Introduction and aim Violence is a widespreading social problem including school aged children and adolescents in Turkey as everywhere in the world. The present study was conducted descriptively to determine the prevalence of bullying among 6th, 7 th and 8 th graders in secondary schools of a city province in Turkey.

Method Universe of the study consists of 3059 students attending secondary schools in Nevsehir province in Turkey. Randomly selected 1287 students were recruited in this cross-sectional study. Ethical approval and institutional permission were 